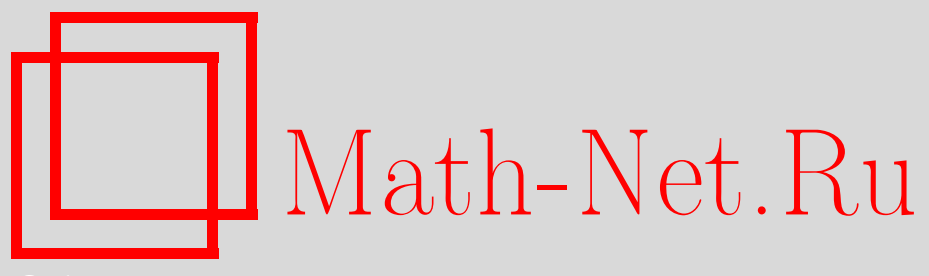

Д. В. Аносов, М. Я. Антоновский, В. М. Бухштабер, В. З. Гринес, А. Ю. Жиров, Е. В. Жужома, Н. Э. Клиншпонт, А. А. Мальцев, Е. А. Сатаев, Я. Г. Синай, А. М. Степин, Л. П. Шильников, Ромен Васильевич Плыкин (некролог), УМН, 2011, том 66, выпуск 3, 199 202

DOI: https://doi.org/10.4213/rm9432

Использование Общероссийского математического портала Math-Net.Ru подразумевает, что вы прочитали и согласны с пользовательским соглашением http://www . mathnet.ru/rus/agreement

Параметры загрузки:

IP : 18.209 .158 .208

26 апреля 2023 г., 15:16:02

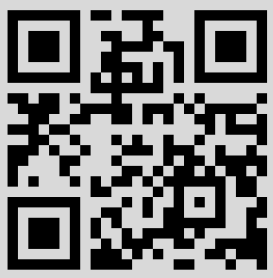




\section{Ромен Васильевич Плыкин}

7 октября 2010 г. скончался Ромен Васильевич Плыкин, один из ведущих специалистов в качественной теории динамических систем.

Р. В. Плыкин родился 5 июля 1935 г. в Тамбове. Его отец, болгарский политэмигрант Христо Паков - известный авиатор, командир летного отряда "Главсевморпуть". Во время Великой Отечественной войны он командовал эскадрильей на фронте, а в 1943 г. был репрессирован. Семья, находясь в эвакуации, не имела о нем никаких сведений и считала погибшим. Через некоторое время мать Ромена Васильевича вторично вышла замуж, а фамилию и отчество он получил от отчима. Освободившись из ГУЛАГа, Х. Паков не нашел семьи и вернулся в Болгарию. Отношения отца и сына возобновились только в 1958 г.

В 1953 г. Р. В. Плыкин окончил среднюю школу в г. Ургенче и поступил на физико-матема-

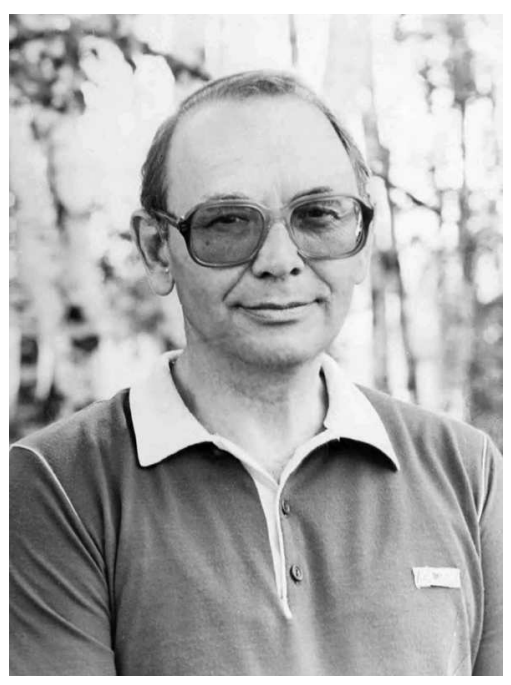
тический факультет Среднеазиатского госуниверситета, который окончил в 1958 г. по специальности математика, после чего преподавал в Ташкентском военном училище и Ташкентском университете, в 1967 г. переехал в г. Калинин (ныне Тверь), где работал в должности доцента кафедры вычислительной математики Политехнического института, а в 1969 г. обосновался в г. Обнинск, где до последних дней оставался профессором Обнинского филиала МИФИ (с 1985 г. Обнинский институт атомной энергетики - ИАТЭ).

Первые опубликованные математические работы Р. В. Плыкина относятся к общей топологии. Они стали основой кандидатской диссертации на тему "Метризация и полнота над полуполями", защищенной в 1964 г. (руководитель М. Я. Антоновский). В этот период большое влияние на Ромена Васильевича оказало знакомство с профессором Московского университета Ю. М. Смирновым, которого он считал одним из своих учителей и с которым поддерживал тесные отношения до самой кончины Юрия Михайловича.

Занятия математикой Р. В. Плыкин совмещал с увлечением альпинизмом, в котором ему удалось достичь заметных успехов. Вскоре он получил возможность применить эти способности. В сентябре 1965 г. в Хумсане (западные отроги Тянь-Шаня) проходила школа по динамическим системам и эргодической теории, собравшая представительный коллектив специалистов и многочисленных слушателей. Там Ромен Васильевич проявил себя квалифицированным и ответственным инструктором во время походов участников школы по горным маршрутам и восхождений на четырехтысячники. Он несомненно был одним из активнейших учеников Хумсанской школы. Записав цикл лекций о гладких динамических системах, он впоследствии 
вместе с лекторами участвовал в доработке этих конспектов для публикации. В значительной мере это предопределило направление его дальнейшей научной работы.

Исследования Р. В. Плыкина в теории динамических систем начались с попыток ответить на вопрос Смейла: всегда ли у типичного диффеоморфизма двумерной сферы существует притягивающая или отталкивающая периодическая орбита? В результате этих попыток им был построен пример диффеоморфизма двумерной сферы с одномерным гиперболическим аттрактором, теперь известным как аттрактор Плыкина. Точнее, это диффеоморфизм, удовлетворяющий аксиоме А. Смейла (множество неблуждающих точек гиперболично и в нем всюду плотны периодические точки), одним из базисных множеств (топологически транзитивных компонент неблуждающего множества) которого является одномерный аттрактор. При этом было установлено, что каждое связное одномерное базисное множество диффеоморфизма двумерной сферы имеет в дополнении до сферы не менее четырех связных компонент (для аттрактора Плыкина их ровно четыре), каждая из которых содержит как минимум одну периодическую точку притяжения или отталкивания. Аттрактор Плыкина обладает необычными топологическими свойствами: он представляет собой неразложимый континуум, локально устроенный как произведение канторова множества на отрезок и являющийся общей границей лежащих в дополнении к нему четырех областей, которые тем самым доставляют пример "озер Вады", известных в общей топологии с начала XX века, а теперь обнаруженных в динамике. Таким образом, пример Плыкина стал одним из тех результатов, которые впоследствии привели к возникновению термина "странный аттрактор". В связи с вопросом о существовании отталкивающих (притягивающих) периодических орбит у диффеоморфизмов поверхностей, отличных от сферы, Ромен Васильевич ввел понятие просторно расположенного базисного множества, дал оценку их числа в зависимости от топологического типа поверхности.

Далее он приступил к изучению гиперболических аттракторов коразмерности 1 в случае многообразий размерности большей двух. В этом направлении Р. В. Плыкин получил фундаментальные результаты о структуре областей притяжения аттракторов указанного класса и дал необходимые и достаточные условия топологической сопряженности диффеоморфизмов на этих областях. Он установил, что в случае ориентируемого аттрактора область притяжения гомеоморфна тору с конечным числом проколов, а в противном случае она двулистно накрывается таким многообразием. Каждый ориентируемый гиперболический аттрактор определяется (с точностью до сопряженности) алгебраическим автоморфизмом тора и конечным набором его периодических орбит. Диффеоморфизм с аттрактором получается из автоморфизма тора посредством многомерного обобщения "хирургической операции" Смейла, которая проводится в окрестности каждой из отмеченных периодических точек. Если аттрактор неориентируем, то для его задания дополнительно нужно зафиксировать инволюцию тора, относительно которой множество отмеченных точек инвариантно. Естественные классы эквивалентности указанных данных (относительно линейных автоморфизмов тора) образуют полные инварианты топологической сопряженности аттракторов. Перечисленные результаты составили основу докторской диссертации "Геометрия и топология гиперболических аттракторов диффеоморфизмов", защищенной Роменом Васильевичем в Математическом институте им. В. А. Стеклова (1984 г.).

В последующих своих работах по теории динамических систем Р. В. Плыкин сформулировал необходимые и достаточные условия гомеоморфности гиперболических аттракторов коразмерности один: в случае многообразий размерности 3 и выше аттракторы гомеоморфны тогда и только тогда, когда автоморфизмы тора, определяющие аттракторы, коммутируют.

Ромен Васильевич увлеченно и с полной отдачей занимался преподаванием математики, которое он считал не менее важным делом, чем сами занятия математикой. Это вполне объяснимо: при открытости его характера для него было необходимо 
общение, особенно с молодежью. С самого начала своей работы в Обнинске он организовал семинар по динамическим системам, на котором были воспитаны многие студенты и аспиранты. Активно участвуя в семинарах по динамическим системам в МИАН и МГУ, он приобщал к этому и своих учеников. Некоторые из них стали математиками и получили ряд интересных результатов.

Р. В. Плыкин был одним из организаторов физико-технической школы при ИАТЭ, долгое время преподавал в этой школе. Он был инициатором создания и президентом научного общества учащихся, организованного при Обнинской станции юных техников, редактором сборников научных трудов учащихся, издаваемых по материалам ежегодных всероссийских конференций школьников "Юность, наука, культура".

Ромен Васильевич был человеком разносторонних интересов: живо интересовался литературой, изобразительным искусством, историей и философией. В его поздних работах обсуждаются вопросы, связанные с концепцией странного аттрактора, ее общенаучное значение и возможные приложения в различных областях науки, в частности, биологии и медицине. Он дружил с философами, поэтами и художниками, сам писал стихи. Люди его любили и тянулись к нему.

Д. В. Аносов, М.Я. Антоновский, В.М. Бухштабер, В. З. Гринес, А.Ю. Жиров, Е.В. Жужома, Н.Э. Клиншпонт, А.А. Мальцев, Е.А. Сатаев, Я.Г. Синай, А.М. Степин, Л. П. Шильников

\section{Список избранных работ Р. В. Плыкина}

[1] "Источники и стоки A-диффеоморфизмов поверхностей", Матем. сб., 94:2 (1974), 243-264; англ. пер.: "Sources and sinks of $A$-diffeomorphisms of surfaces", Math. USSR-Sb., 23:2 (1974), 233-253.

[2] "О существовании притягивающих (отталкивающих) периодических точек $A$-диффеоморфизмов проективной плоскости и бутылки Клейна", $У M H, \mathbf{3 2 : 3}$ (1977), 179.

[3] "Одномерные плоские соленоиды и некоторые их приложения", Докл. АН СССР, 232:4 (1977), 756-759 (совм. с А. Ю. ЖКировым, Д. А. Камаевым); англ. пер.: "One-dimensional plane solenoids and some of their applications", Soviet Math. Dokl., 18:1 (1977), 130-134 (with A. Yu. Jirov, D. A. Kamaev).

[4] "Coexistence, geometrical and asymptotical properties of hyperbolic codimension one attractors. Application to diffeomorphisms with infinitely many zero-dimensional attractors", Dynamical systems, v. III (Warsaw), Astérisque, 51, Soc. Math. France, Paris, 1978, 347-353.

[5] "One-dimensional attractors of $A$-diffeomorphism on $S^{2}$ and diffeomorphisms with infinitely many sinks", Dynamical systems, v. III (Warsaw), Astérisque, 51, Soc. Math. France, Paris, 1978, 355-394 (with A. Yu. Zhirov, D. A. Kamaev).

[6] "О гиперболических аттракторах диффеоморфизмов", УМН, 35:3 (1980), 94-104; англ. пер.: "Hyperbolic attractors of diffeomorphisms", Russian Math. Surveys, 35:3 (1980), 109-121.

[7] "О гиперболических аттракторах диффеоморфизмов (неориентируемый случай)", УМH, 35:4 (1980), 205-206; англ. пер.: "On hyperbolic attractors of diffeomorphisms (The non-orientable case)", Russian Math. Surveys, 35:4 (1980), $186-187$.

[8] "Hyperbolic attractors of differentiable dynamical systems", Nonlinear dynamics and turbulence, Interaction Mech. Math. Ser., Pitman, Boston, MA, 1983, 281-294.

[9] "О геометрии гиперболических аттракторов гладких каскадов”, УМН, 39:6 (1984), 75-113; англ. пер.: "On the geometry of hyperbolic attractors of smooth cascades", Russian Math. Surveys, 39:6 (1984), 85-131. 
[10] "Странные аттракторы", Динамические системы с гиперболическим поведением, Динамические системы - 9, Итоги науки и техники. Соврем. проблемы матем. Фундам. напр., 66, ВИНИТИ, М., 1991, 100-148 (совм. с Е. А. Сатаевым, С. В. Шлячковым); англ. пер.: "Strange attractors", Dynamical systems, IX, Encyclopaedia Math. Sci., 66, Springer, Berlin, 1995, 93-139 (with E. A. Sataev, S. V. Shlyachkov).

[11] "Some problems of attractors of dynamical systems", Topology Appl., 54:1-3 (1993), 19-46 (with A. Yu. Zhirov).

[12] "Соответствие между одномерными гиперболическими аттракторами диффеоморфизмов поверхностей и обобщенными псевдоаносовскими диффеоморфизмами", Матем. заметки, 58:1 (1995), 149-152 (совм. с А. Ю. Жировым); англ. пер.: "On the relationship between one-dimensional hyperbolic attractors of surface diffeomorphisms and generalized pseudo-Anosov diffeomorphisms", Math. Notes, 58:1 (1995), 779-781 (with A. Yu. Zhirov).

[13] "О структуре централизаторов аносовских диффеоморфизмов тора", УМH, 53:6 (1998), 259-260; англ. пер.: "The structure of the centralizers of Anosov diffeomorphisms of the torus", Russian Math. Surveys, 53:6 (1998), 1363-1364.

[14] "Exact upper bounds for the number of one-dimensional basic sets of surface A-diffeomorphisms", J. Dynam. Control Systems, 3:1 (1997), 1-18 (with S. Kh. Aranson, A. Yu. Zhirov, E. V. Zhuzhoma).

[15] "К проблеме топологической классификации странных аттракторов динамических систем", УМH, 57:6 (2002), 123-166; англ. пер.: "On the problem of topological classification of strange attractors of dynamical systems", Russian Math. Surveys, 57:6 (2002), 1163-1205.

[16] "Странные аттракторы $A$-каскадов", УМH, $\mathbf{5 9 : 2 ~ ( 2 0 0 4 ) , ~ 1 9 7 - 1 9 8 ; ~ а н г л . ~ п е р . : ~}$ "Strange attractors of A-cascades", Russian Math. Surveys, 59:2 (2004), 390-392.

[17] "Geometrical and dynamical properties of Lorenz type system", J. Phys.: Conf. Ser., 23 (2005), 96-104 (with E. A. Sataev, N. E. Klinshpont).

[18] "Некоторые теоретические и экспериментальные факты функционирования нервной системы", Сборник научных работ лауреатов областных премий и стипендий, вып. 6, КГПУ им. К.Э. Циолковского, Калуга, 2010, 116-126 (совм. с О. А. Мирзеабасовым, Н.Э. Клиншпонт, М. И. Шарлаем, Н. Н. Николаевым).

[19] "Strange attractors. Topologic, geometric and algebraic aspects", Regul. Chaotic Dyn., 15:2-3 (2010), 335-347 (with N. E. Klinshpont). 